\title{
RESÍDUOS DE ANTIBIÓTICOS NO LEITE: CAUSAS E IMPACTOS PARA A INDÚSTRIA E SAÚDE PÚBLICA
}

\author{
LOBATO, Cláudio Luiz Damé Sayão ${ }^{1}$; \\ DE LOS SANTOS, João Rodrigo Gil ${ }^{2}$.
}

Recebido: 22/10/2019

Aceito: $17 / 12 / 2019$

\begin{abstract}
${ }^{1}$ Médico Veterinário, Mestre, Secretaria de Desenvolvimento Rural de Palmas, Curso de Mestrado Profissional
em Ciência e Tecnologia de Alimentos - FAEM, UFPEL; ${ }^{2}$ Médico Veterinário, Professor, Doutor, Departamento de Veterinária Preventiva, Faculdade de Veterinária, Curso de Mestrado Profissional em Ciência e Tecnologia de

Alimentos - FAEM, UFPEL.
\end{abstract}

\section{RESUMO}

$\mathrm{O}$

leite é um dos principais alimentos consumidos pela população brasileira e, para tanto, a legislação sanitária e de controle de alimentos vem sendo atualizada constantemente como forma de garantia de segurança alimentar. O leite contaminado por resíduos de antimicrobianos é considerado adulterado e impróprio para o consumo, representando prejuízos à indústria de laticínios e riscos à saúde do consumidor, já que pode acarretar uma série de prejuízos nos processos de produção industrial, além da possibilidade de desenvolvimento de reações alérgicas ou tóxicas. Este trabalho teve por objetivo discutir as causas e os impactos da presença de resíduos de antibióticos no leite, para a indústria e saúde pública.

Palavras-chave: Leite. Antimicrobianos. Resíduos. Legislação. 


\section{INTRODUÇÃO}

O Brasil é um dos principais produtores de alimentos e ocupava o quarto lugar no ranking de produção mundial de leite em 2017 (EMBRAPA, 2018). Em 2018, foram adquiridos 24,45 bilhões de litros, representando um aumento de 0,5\% em relação ao ano anterior (IBGE, 2019). Para a população brasileira, o leite é um importante componente nutricional, principalmente no grupo de crianças e idosos, tendo um consumo estimado em 173 litros por habitante ao ano (EMBRAPA, 2018).

Entende-se por leite, sem outra especificação, o produto oriundo da ordenha completa, ininterrupta, em condições de higiene, de vacas sadias, bem alimentadas e descansadas (BRASIL, 2017). É um excelente alimento pelo seu valor nutritivo, portanto, merece ser tratado com todo o cuidado necessário, a fim de que não venha causar danos à saúde do consumidor (BRASIL, 2011). Nesse contexto, o estado de saúde das vacas leiteiras deve ser controlado para que não constituam riscos para a saúde pública.

Vários são os fatores que podem provocar alterações na composição do leite, dentre eles, a utilização de medicamentos (FERNANDES; MARICATO, 2010). Nos últimos anos, a presença de resíduos químicos, especialmente antibióticos, em alimentos de origem animal, se tornou um problema de saúde pública (SCHLEMPER; SACHET, 2017). Os resíduos de antibióticos no leite, em geral, representam risco à saúde do consumidor e interferem na produção de derivados (ANADÓN; MARTÍNEZ-LARRAÑAGA, 1999). Mastites e outras infecções que acometem rebanhos leiteiros são tratadas com antibióticos e, se não houver o manejo adequado dessas drogas no controle da enfermidade, tornam-se a principal origem para a presença de resíduos no leite (MARTIN, 2011). Nesse sentido, para que os medicamentos administrados nos rebanhos leiteiros não sejam maléficos à saúde pública, é iminente a necessidade do controle na utilização das drogas veterinárias (OMS, 2009).

Cada vez mais têm sido detectados resíduos de antimicrobianos no leite em diferentes países. Nos Estados Unidos foi encontrada flunixina em leite coletado de caminhões tanque (KISSELL et al., 2013). No Irã, amostras de leite obtidas em centros de coleta de leite cru, em fábricas de produção de leite pasteurizado e em leite pasteurizado distribuído nas escolas foram positivas para vários tipos de antibióticos (MOGHADAM et al., 2016). Em Kosovo, leite 
cru coletado em fazendas individuais e pontos de coleta de leite foram positivos para amoxicilina, penicilina $G$ e cloxacilina (RAMA et al, 2017). No Nepal, leite fresco obtido de produtores, laticínios caseiros e cooperativas apresentaram penicilinas e sulfonamidas (KHANAL et al., 2018). No Kenia, o leite oriundo de máquinas de venda apresentaram vários antibióticos (KOSGEY et al., 2018). Da mesma forma, na Itália, amostras de leite disponíveis no mercado foram positivas para vários tipos de antimicrobianos (IZZO et al., 2020). Esses resultados indicam que os resíduos de antibióticos no leite podem ser um desafio de ordem mundial.

Seguindo esse cenário, no Brasil, têm ocorrido casos positivos em vários estados (Figura 1). Nero et al. (2007) verificaram a presença de resíduos de antibióticos em leite cru, coletado em quatro regiões produtoras do Brasil (PR, SP, MG e RS). Pacheco-Silva et al. (2014) avaliaram resultados do Programa de Análise de Resíduos de Medicamentos Veterinários em Alimentos de Origem Animal (PAMVET) e do Plano Nacional de Controle de Resíduos e Contaminantes (PNCRC) e observaram presença de resíduos de antimicrobianos no leite em praticamente todos os anos, de 2002 a 2011. Prado et al. (2015) detectaram tetraciclinas em leite pasteurizado no Paraná. Novaes et al. (2017) avaliaram amostras de leite comercializado no varejo das cinco regiões brasileiras e detectaram resíduos, embora baixos, de diversos tipos de antibióticos, incluindo norfloxacino, o qual não possuía Limite Máximo de Resíduo (LMR) estabelecido e, dessa forma, não deveria ter sido detectado.

\begin{tabular}{|c|c|c|c|c|}
\hline Referência & $\begin{array}{l}\text { Estado ou } \\
\text { região }\end{array}$ & Teste & $\begin{array}{c}\text { Resultado } \\
\text { positivo } \\
\text { (\%) }\end{array}$ & Amostra \\
\hline Mattos et al. (2010) & $\mathrm{PE}$ & inibição bacteriana & 1,89 & Leite cru \\
\hline Sousa et al. (2012) & CE & inibição bacteriana & 13,33 & Leite pasteurizado tipo $\mathrm{C}$ \\
\hline Vieira et al. (2012) & PR & inibição bacteriana & 19 & Leite pasteurizado \\
\hline Cassoli et al. (2013) & Sudeste & inibição bacteriana & 0,91 & Leite cru resfriado \\
\hline Silva et al. (2014) & PA & inibição bacteriana & 8 & Leite in natura \\
\hline Ferreira et al. (2014) & $\mathrm{PI}$ & inibição bacteriana & 2,33 & Leite in natura \\
\hline Santos et al. (2014) & SP & Inibição bacteriana & 8,33 & Leite cru \\
\hline Prado et al. (2015) & PR & cromatografia & 3 & Leite pasteurizado \\
\hline Alves et al. (2016) & RO & $\begin{array}{c}\text { inibição bacteriana e } \\
\text { imunoenzimático }\end{array}$ & 0,039 & Leite cru \\
\hline Nunes et al. (2016) & $\mathrm{PE}$ & Inibição bacteriana & 14,29 & Leite in natura \\
\hline Schlemper e Sachet (2017) & PR & Imunoenzimático & 27 & Leite cru e pasteurizado \\
\hline Souza et al. (2017) & $\mathrm{RN}$ & inibição bacteriana & 6,72 & Leite cru \\
\hline
\end{tabular}

Figura 1 - Resultados de pesquisas sobre resíduos de antibióticos em leite comercializado no Brasil. 
Os resultados do monitoramento do PNCRC referente ao acompanhamento da presença de antimicrobianos em leite, entre os anos de 2010 a 2018, nos quais foram avaliadas amostras aleatórias de leite in natura e com sorteio dos estabelecimentos, indicaram uma ocorrência média de 0,45\% de amostras com não conformidades (BRASIL, 2019a).

A demanda cada vez maior por produtos de origem animal de qualidade, por parte dos agentes comerciais nacionais e internacionais, assim como do mercado consumidor, exige um rigoroso controle do leite e derivados produzidos, tornando-se necessária a aplicação de medidas adequadas para que sejam garantidas sua inocuidade, idoneidade e certificação de qualidade (COSTA et al., 2009; MARTIN, 2011).

Este trabalho teve como objetivo discutir as causas e os impactos da presença de resíduos de antibiótico no leite para a indústria e saúde pública.

\section{LEGISLAÇÃO E RESÍDUOS DE ANTIBIOTICOS NO LEITE}

No modelo atual, para regular as relações produção-consumo de alimentos no Brasil, há uma notória divisão de responsabilidades entre o Ministério da Saúde (MS) e o Ministério da Agricultura, Pecuária e Abastecimento (MAPA) (SPISSO et al., 2009). O MAPA é responsável pelo registro e a fiscalização de produtos de uso veterinário e dos estabelecimentos que os fabriquem e/ou comercializem. Já a avaliação e fiscalização da qualidade dos alimentos de origem animal é atribuição dividida entre a Agência Nacional de Vigilância Sanitária (ANVISA) e o MAPA (FUSCO et al., 2010).

Com a proposta de não deixar os consumidores expostos à nocividade de resíduos e contaminantes, assim como controlar as substâncias de uso na agropecuária, o governo brasileiro criou, em 1979, o Programa Nacional de Controle de Resíduos Biológicos em Carnes (PNCRBC), através da Portaria no 86/79 do MAPA, revogada em 1986 pela Portaria no 51, instituindo o Programa Nacional de Controle de Resíduos Biológicos em Produtos de Origem Animal (PNCRB), adequada, mais tarde, pela Portaria no 527/95. Em 1999, o PNCRB foi renomeado para "Plano Nacional de Controle de Resíduos em Produtos de Origem Animal - PNCR", ocorrendo alterações nos Programas de Controle de Resíduos, dentre eles, o Leite - PCRL, através da Instrução Normativa (IN) no 42 (SPISSO et al., 2009). A IN no 42 declara a competência do Ministério da Saúde para estabelecer os limites máximos de 
resíduos (LMRs) e no caso de não estarem estabelecidos, serão utilizados os valores internalizados no MERCOSUL, os recomendados pelo Codex Alimentarius, os constantes nas Diretivas da União Européia e os utilizados pelo FDA/USA (BRASIL, 1999).

O LMR é a concentração máxima de resíduos, resultante da utilização de um medicamento veterinário, aceitável em alimentos. Esse limite baseia-se no tipo e na quantidade de resíduos que não apresentam risco de toxicidade para a saúde humana, levando-se em consideração a Ingestão Diária Aceitável (IDA) e que, se ingerida durante toda a vida do indivíduo, não apresenta riscos a sua saúde (ANVISA, 2009).

Com o objetivo de operacionalizar a competência legal de controlar e fiscalizar resíduos de medicamentos veterinários em alimentos, foi desenvolvido pela ANVISA, em 1999, o PAMVET. Com início em 2002, sua primeira matriz de análise foi o leite bovino (ANVISA, 2009). A escolha da pesquisa de antimicrobianos no leite baseou-se, dentre vários critérios, no fato de que a presença de resíduos no alimento oferece um risco potencial à saúde pública e ao potencial de exposição do consumidor. Para a interpretação dos resultados obtidos neste Programa, utilizaram-se LMRs de medicamentos veterinários acordados no âmbito do Mercosul (MERCOSUL, 2000). Para os medicamentos veterinários cujos valores de LMRs não estavam estabelecidos nos regramentos técnicos do Mercosul, utilizaram-se os valores preconizados pelo Codex Alimentarius e, na ausência destes, aqueles estabelecidos pela União Europeia (Figura 2) (ANVISA, 2009). Da mesma forma, com o intuito de de promover segurança química dos alimentos de origem animal produzidos no Brasil, o MAPA estabele anualmente os LMRs através do PNCRC (Figura 2) (BRASIL, 2019b). 


\begin{tabular}{|c|c|c|c|}
\hline $\begin{array}{c}\text { Grupo de } \\
\text { antimicrobianos }\end{array}$ & Substância Farmacologicamente Ativa & $\begin{array}{l}\mathrm{LMR}^{\mathrm{a}} \\
(\mu \mathrm{g} / \mathrm{L})\end{array}$ & Referência \\
\hline \multirow{9}{*}{$\beta$-lactâmicos } & Penicilinas: & & \\
\hline & Benzilpenicilina/benzilpenicilina procaine & 4 & Mercosul \\
\hline & Ampicilina, Amoxiciclina & 4 & Mercosul \\
\hline & Cloxacilina, Oxacilina, Dicloxacilina & 30 & União Européia \\
\hline & Cefalosporinas: & & \\
\hline & Ceftiofur & 100 & Mercosul \\
\hline & Cefapirina & 60 & União Européia \\
\hline & Cefazolin & 50 & União Européia \\
\hline & Cefoperazone & 50 & União Européia \\
\hline \multirow{2}{*}{ Aminoglicosídeos } & Diidroestreptomicina/Estreptomicina & 200 & Mercosul \\
\hline & Neomicina & 500 & Mercosul \\
\hline Macrolídeo & Eritromicina & 40 & Mercosul \\
\hline Tetraciclinas & Oxitetraciclina, Tetraciclina, Clortetraciclina & 100 & Mercosul \\
\hline \multirow{3}{*}{ Anfenicóis } & Cloranfenicol & 0 & Mercosul \\
\hline & Florfenicol $^{\mathrm{C}}$ & $N D^{b} / 10$ & - \\
\hline & Tianfenicol $^{\mathrm{d}}$ & $50 / 10$ & União Européia \\
\hline Sulfonamidas & Sulfametazina, Sulfametoxina, Sulfatiazol & 100 & Mercosul \\
\hline
\end{tabular}

Figura 2 - Limites Máximos de Resíduos de antimicrobianos em leite estabelecidos pela ANVISA (PAMVET) e

$\mathrm{LMR}^{\mathrm{a}}$ : Limite Máximo de Referência para ANVISA e MAPA. MAPA (PNCRC).

$N D^{b}$ : Não definido.

Florfenicol ${ }^{\mathrm{c}}$ : Valor não definido no PAMVET e referenciado como $10 \mu \mathrm{g} / \mathrm{L}$ no PNCRC 2019.

Tianfenicol $^{\mathrm{d}}$ : Valor de $50 \mu \mathrm{g} / \mathrm{L}$ definido no PAMVET e referenciado como $10 \mu \mathrm{g} / \mathrm{L}$ no PNCRC 2019.

Fonte: adaptado de ANVISA (2009), PACHECO-SILVA et al. (2014) e BRASIL (2019).

Com a implantação da IN no 51, em 2002, o MAPA estabeleceu novas regras para a monitorização da produção, identidade e qualidade do leite. E a necessidade da realização de, pelo menos, uma análise mensal do leite para todos os locais processadores do alimento, a ser efetuada em uma unidade operacional da Rede Brasileira de Laboratórios para Controle da Qualidade do Leite. Estabeleceu, ainda, que os métodos analíticos empregados junto aos estabelecimentos beneficiadores de leite e a pesquisa de resíduos de antibióticos no leite, devem apresentar sensibilidade para os LMRs adotados pelo MAPA (BRASIL, 2002).

Em 2011, foi publicada a IN no 62, do MAPA, que, apesar de alterar alguns anexos referentes ao regulamento técnico de produção, identidade e qualidade do leite da IN n은 51, manteve os parâmetros de composição para avaliação da qualidade do leite e pesquisa de resíduos de antibióticos no leite (BRASIL, 2011). 
Com a publicação da IN no 11, de 2012, o MAPA instituiu o Subprograma de Monitoramento em Carnes (bovina, aves, suína e equina), Leite, Pescado, Mel, Ovos e Avestruz para o exercício de 2012, referente ao Plano Nacional de Controle de Resíduos Biológicos em Produtos de Origem Animal - PNCRB, determinando o caráter aleatório da amostragem, com sorteio dos estabelecimentos onde seriam colhidas as amostras. Sendo as amostras enviadas para os laboratórios oficiais e credenciados, pertencentes à Rede Nacional de Laboratórios Agropecuários do SUASA (Sistema Unificado de Atenção à Sanidade Agropecuária). Definindo o grupo dos contaminantes, os métodos de análise para cada analito, a matriz, os limites de referência ( $\mu \mathrm{g} / \mathrm{L})$ e o número de ensaios (BRASIL, 2012).

Em 2018, o MAPA publicou a IN no 31, que determinou prazos de vigência e alterou padrões de qualidade de Contagem Bacteriana Total (CBT) e Contagem de Células Somáticas (CCS) presentes no leite cru refrigerado, entretanto, não houve modificações dos critérios para pesquisa de resíduos de antibióticos ou outros inibidores de crescimento microbiano (BRASIL, 2018a). Ainda em 2018, o MAPA publicou as Instruções Normativas no 76 e № 77, que fixaram novas regras para a produção, especificando os padrões de qualidade do leite cru refrigerado, do pasteurizado e do leite tipo A. A IN no 76 aprovou o regulamento técnico de identidade e qualidade do leite cru refrigerado, devendo não apresentar resíduos de produtos de uso veterinário e contaminantes acima dos LMRs previstos em normas complementares (BRASIL, 2018b). Já a IN no 77, no seu Art. 5으, entre outras determinações, proíbe o envio, a qualquer estabelecimento industrial, do leite de fêmeas que, independentemente da espécie, estejam sendo submetidas a tratamento com produtos de uso veterinário durante o período de carência recomendado pelo fabricante (BRASIL, 2018c).

\section{CAUSAS DE RESÍDUOS DE ANTIBIÓTICOS NO LEITE}

De acordo com a Organização Mundial da Saúde (OMS, 2009), o leite pode ser contaminado por resíduos de medicamentos veterinários, pesticidas ou outros contaminantes químicos. Portanto, a utilização das boas práticas veterinárias, no que tange à saúde da vaca leiteira, ao emprego de métodos adequados de ordenha e à utilização correta de medicamentos autorizados, deve ser buscada para que se obtenha uma produção inócua e idônea.

Os resíduos podem ser detectados no leite após os animais receberem a medicação pelas 
vias: intravenosa, intramuscular, oral, subcutânea, intramamária, intrauterina ou tópica (MITCHELL et al., 1998). Em 1980, a legislação brasileira estipulou o prazo mínimo para o aproveitamento do leite de animais que necessitassem submeter-se a tratamento com antibióticos, sendo de 72 horas a partir da última aplicação da droga (BRASIL, 1980). Porém, o período de eliminação de antimicrobianos no leite depende da via de inoculação, dosagem, estado fisiológico da glândula mamária e a classe de antibiótico utilizada, podendo chegar até a seis dias (Tabela 1) (COSTA, 2000; 2015).

Tabela 1 - Duração mínima de eliminação de antimicrobianos pelo leite administrados via intramamária.

\begin{tabular}{lc}
\hline Antimicrobiano & Período mínimo de eliminação (dias) \\
\hline Penicilina G (procaína) & 2 \\
Clortetraciclina & 6 \\
Oxitetraciclina & 4 \\
Estreptomicina & 4 \\
\hline
\end{tabular}

Fonte: Adaptado de Costa (2000; 2015).

Segundo Jones e Seymour (1988), a fonte de resíduos de antibióticos no leite pode ter várias origens, dentre elas, o uso indevido de drogas no controle de mastites, uma das principais enfermidades do gado leiteiro, e que requer tratamento com antimicrobianos, sendo considerada a origem primária de resíduos no leite (SANTOS; FONSECA, 2007).

Os antimicrobianos e seus metabólicos podem depositar-se ou acumular-se nas células, nos tecidos ou nos órgãos do animal e, quando vestígios dessas substâncias são detectadas posteriormente nos alimentos, são denominadas de resíduos (BRITO, 2000). Outras causas para que se constatem resíduos de antimicrobianos no leite são: falhas na observação ou não cumprimento dos períodos de carência dos antimicrobianos administrados, uso de dosagem acima da recomendada, uso de medicamentos por períodos muito prolongados, uso de medicamentos com períodos de excreção prolongados ou mistura acidental de leite não contaminado com leite contaminado, ocasionado por problemas ou falhas na identificação dos animais tratados (JONES; SEYMOUR, 1988). Outra condição, que pode determinar a presença de resíduos no leite, é a adição intencional de drogas para encobrir a 
deficiência na qualidade higiênica do leite, visando aumentar seu tempo de vida útil (BRASIL, 1993).

No Brasil, a presença desses resíduos no leite, por falhas de manejo, é cada vez mais comum. Em investigação realizada por Lopes (2002), na região metropolitana de Curitiba (PR), foi evidenciado que, de 80 produtores que administravam antimicrobianos no rebanho leiteiro, 16,8\% não respeitavam o período de carência, 30,1\% utilizavam medicamentos não autorizados para vacas lactantes e 45,6\% administravam uma superdosagem. Monteiro et al. (2007) citaram que, de 16 produtores da região Agreste do estado de Pernambuco que utilizaram antimicrobianos em animais em lactação no tratamento de mastite, 6,3\% não descartavam o leite, 37,5\% descartavam todo o leite e $56,3 \%$ descartavam apenas o leite dos quartos em tratamento, indicando que os produtores desconheciam o manejo adequado do leite proveniente de animais sob tratamento com antimicrobianos.

Além do manejo dos quartos tratados, outra prática que pode gerar resíduos de antimicrobianos no leite, é o tratamento de vacas secas (TETENS et al., 2019). Estevão Neto et al. (2015), avaliaram a presença de resíduos de antibióticos no leite de animais tratados no período pré-parto, com antibióticos comerciais específicos para uso em período seco e em lactação, aos 60 e 30 dias pré-parto, respectivamente, em uma única aplicação. No período de 5 a 10 dias pós-parto, foram constatadas 6,38\% de amostras positivas. Da mesma forma, Bachmann et al. (2018) determinaram a concentração de resíduos no leite, de cefquinoma administrado por via intramamária, em vacas secas, nos dias 21, 14 e 7 antes da data calculada do parto e indicaram que curtos períodos de secagem não devem ser utilizados no manejo da vaca seca, pois levam a um máximo de 31,3 $\pm 1,2$ ordenhas e 19,4 \pm 0,4 dias após o tratamento com resíduos de cefquinoma acima do LMRs.

\section{IMPACTOS DA PRESENÇA DE ANTIBIÓTICOS NO LEITE}

Diversos estudos realizados indicam prejuízos causados ao setor industrial quanto à presença dos resíduos de antibióticos no leite. Segundo Brito e Lange (2005), o principal problema na utilização dos antibióticos para a indústria é a inibição de culturas lácteas sensíveis, utilizadas na fabricação de iogurtes, queijos e outros produtos fermentados, 
provocando problemas na qualidade e obtenção desses produtos, além da formação de odores desagradáveis no creme e na manteiga. Jones (2009) relata que a concentração de 1 parte por bilhão (ppb) de antibiótico pode interferir nos processos iniciais para a fabricação de manteiga, iogurte e queijos.

Schenck e Friedman (2000), ao avaliarem se o transporte do leite à temperatura de $4{ }^{\circ} \mathrm{C}$ acarretaria algum prejuízo à atividade da ampicilina no leite cru, constataram que após estocagem durante seis dias, à temperatura de $4{ }^{\circ} \mathrm{C}$, houve pouca ou nenhuma perda da concentração inicial de 20 ppb. Roca et al. (2011), confirmaram que a maioria dos tratamentos térmicos utilizados nos laticínios não impedem que resíduos de antimicrobianos cheguem ao mercado consumidor e, dessa forma, seus derivados também estarão contaminados.

Os antibióticos $\beta$-lactâmicos (penicilinas e cefalosporinas) formam o grupo de drogas antimicrobianas mais utilizado para a prevenção e tratamento de mastites e outras infecções bacterianas em vacas leiteiras, e o de maior frequência de identificação de resíduos no leite (KORB et al., 2011). O leite contaminado pode levar a problemas ligados à saúde pública, com possibilidade de desenvolvimento de reações alérgicas ou tóxicas. As reações alérgicas são relacionadas principalmente às penicilinas, mas estreptomicina, sulfonamidas e tetraciclina também podem causar esse tipo de reação e se manifestam, geralmente, como asma brônquica, urticárias, dermatites ou rinites. Reações tóxicas são relacionadas a alguns antimicrobianos com potencial carcinogênico, isto é, que podem desenvolver tumores em animais de laboratório (como sulfametazina e nitrofuranos) ou dar origem a alterações hematológicas em indivíduos susceptíveis (BRITO; LANGE, 2005). Outros problemas acarretados à saúde do consumidor são: a hipersensibilidade e possível choque anafilático (DAYAN, 1993), a seleção de cepas resistentes no ambiente (COSTA, 1996; BRITO, 2000) e possibilidade de interferência na microbiota intestinal (BRITO; BRITO, 1998; BRITO, 2000).

O uso indiscriminado de antibióticos na produção animal tem contribuido para o desenvolvimento da resistência bacteriana. Fuller (1989) cita que a utilização indiscriminada e rotineira dos antibióticos têm levado ao aparecimento de populações bacterianas resistentes, gerando desequilíbrio na simbiose entre microrganismos não patogênicos e o 
animal. Para Nijsten et al. (1993) a resistência bacteriana pode ser transferida por mecanismos diversos e estabelecer-se entre microrganismos de uma mesma população ou de diferentes populações, como da microbiota animal para humana e vice-versa. Em investigação realizada por Machado et al. (2008), com um total de 109 cepas de Staphylococcus sp. coagulase negativa, isolados de leite de vacas com mastite clínica e subclínica, em nove estados brasileiros, foi observada a resistência de todas as cepas a pelo menos uma das drogas testadas. Aqib et al. (2017) encontraram 34\% de prevalência de Staphylococcus aureus resistente à meticilina em amostras de leite bovino no Paquistão. Tempini et al. (2018) isolaram Escherichia coli multiresistente (2/10) de leite coletado em tanque nos Estados Unidos. Qu et al. (2019) verificaram alta prevalência de genes resistentes a antimicrobianos em Staphylococcus sp. isolados de vacas com mastite clínica na China. Esses resultados sugerem a presença de microrganismos resistentes a antimicrobianos dentro dos sitemas de produção de leite sendo, provavelmente, uma consequência do uso intensivo e incorreto de drogas antimicrobianas.

\section{CONCLUSÃO}

Inúmeros experimentos demonstraram a ocorrência de falhas na administração de antimicrobianos em vacas leiteiras, ocasionando problemas para as indústrias e para a saúde da população. Os erros de dosagem e a utilização de antimicrobianos sem respeito ao período de carência, têm gerado resíduos no leite, o que acarreta em matéria-prima imprópria para a indústria e alimento inadequado para o consumo humano, causando prejuízos sociais e econômicos. É evidenciada a importância dos procedimentos de boas práticas com relação ao manejo da produção, em especial à higiene da ordenha e o respeito ao período de carência dos antimicrobianos utilizados na bovinocultura leiteira, assegurando o cumprimento da legislação em vigor e garantindo um alimento seguro à população. 


\section{ANTIBIOTIC RESIDUES IN MILK: CAUSES AND IMPACTS FOR INDUSTRY AND PUBLIC HEALTH}

\section{ABSTRACT}

$\mathrm{M}$ ilk is one of the main foods consumed by the Brazilian population and for that, sanitary and food control legislation have been constantly updated as a way to guarantee food security. Milk contaminated with antimicrobial residues is considered adulterated and unappropriatedt for consumption, causing losses to the dairy industry and risks to the consumer's health, since it can take to allergic or toxic reactions. The objective of this article is to discuss the causes and impacts of the presence of antibiotic residues in milk for the industry and public health.

Keywords: Milk. Antimicrobials. Residues. Legislation.

\section{RESIDUOS DE ANTIBIÓTICO EN LA LECHE: CAUSAS E IMPACTOS PARA LA INDUSTRIA Y LA SALUD PÚBLICA}

\section{RESUMEN}

a leche es uno de los principales alimentos consumidos por la población brasilera y para tanto, la legislación sanitaria y de control de alimentos viene siendo actualizada constantemente como forma de garantizar la seguridad alimentaria. La leche contaminada por residuos de antimicrobianos es considerada adulterada e impropia para el consumo, representando riesgos para la industria lechera y la salud del consumidor, dado que puede acarrear una serie de prejuicios en los procesos de producción industrial y llevar al desarrollo de reacciones alérgicas o tóxicas. Este trabajo tiene por objetivo discutir las causas y los impactos de la presencia de residuos de antibiótico en la leche para la industria y la salud pública.

Palabras clave: Leche. Antimicrobianos. Residuos. Legislación. 


\section{REFERÊNCIAS}

ALVES, G. M. C.; MARTINOTTO, G.; BERTIPAGLIA, L. M. A.; et al. Avaliação de resíduos de antibióticos no leite no recebimento de matéria-prima em latícinios no estado de Rondônia. Boletim Técnico da Universidade Camilo Castelo Branco, n. 16, p. 1-16, 2016. Disponível em: <https://universidadebrasil.edu.br/portal/_biblioteca/uploads/20190610152929.pdf> .

ANADÓN, A.; MARTÍNEZ-LARRAÑAGA, M. R. Residues of antimicrobial drugs and feed addistives in animal products: regulatory aspects. Livestock Production Science, v. 59, n. 23, p. 183-198, 1999.

ANVISA - AGÊNCIA NACIONAL DE VIGILÂNCIA SANITÁRIA. Programa de Análise de Resíduos de Medicamentos Veterinários em Alimentos de Origem Animal - PAMVET, Relatório 2006-2007. Brasília: ANVISA, 2009.76p. Disponível em: $<$ http://portal.anvisa.gov.br/documents/33916/395364/PAMVet+Monitoramento+de+Res\%C3\%ADduos+em+Leite+Exposto+ao+Consumo++Relat\%C3\%B3rio+2006-2007/4777c371-e5b5-42e0-9c3f-43670009a802> .

AQIB, A. I.; IJAZ, M.; ANJUM, A. A.; et al. Antibiotic susceptibilities and prevalence of Methicillin resistant Staphylococcus aureus (MRSA) isolated from bovine milk in Pakistan. Acta Tropica, v. 176, p. 168-172, 2017.

BACHMANN, J.; HELMSCHRODT, C.; RICHTER, A.; et al. Residue concentration of cefquinome after intramammary dry cow therapy and short dry periods. Journal of Dairy Science, v. 101, n. 8, p. 7540-7550, 2018.

BRASIL. MINISTÉRIO DA AGRICULTURA, PECUÁRIA E ABASTECIMENTO. Secretaria Nacional de Defesa Agropecuária, Portaria no 005, de 24 de abril de 1980, dispõe sobre normas para produção e beneficiamento de leite pasteurizado de consumo direto. Diário Oficial da União, publicado em 25/04/1980, seção 1, p. 54, 1980.

BRASIL. MINISTÉRIO DA AGRICULTURA, PECUÁRIA E ABASTECIMENTO. Portaria no 101, de 11 de agosto de 1993. Diário Oficial da União, publicado em 17/08/1993, edição 156, seção 1, p. 11937-11945, 1993.

BRASIL. MINISTÉRIO DA AGRICULTURA, PECUÁRIA E ABASTECIMENTO. Instrução Normativa no 42, de 20 de dezembro de 1999. Diário Oficial da União, publicado em 22/12/1999, edição 244, seção 1, p. 213-227, 1999.

BRASIL. MINISTÉRIO DA AGRICULTURA, PECUÁRIA E ABASTECIMENTO. Instrução Normativa no 51, de 18 de setembro de 2002. Diário Oficial da União, publicado em 20/09/2002, edição 183, seção 1, p. 13-22, 2002. 
BRASIL. MINISTÉRIO DA AGRICULTURA, PECUÁRIA E ABASTECIMENTO. Instrução Normativa no 62, de 29 de dezembro de 2011. Diário Oficial da União, publicado em 30/12/2011, edição 251, seção 1, p. 6-11, 2011.

BRASIL. MINISTÉRIO DA AGRICULTURA, PECUÁRIA E ABASTECIMENTO. Instrução Normativa no 11, de 22 de maio de 2012. Diário Oficial da União, publicado em 25/05/2012, edição 101, seção 1, p. 4-8, 2012.

BRASIL. MINISTÉRIO DA AGRICULTURA, PECUÁRIA E ABASTECIMENTO. Decreto no 9.013, de 29 de março de 2017. Dispõe sobre o regulamento da inspeção industrial e sanitária de produtos de origem animal. Diário Oficial da União, publicado em 30/03/2017, edição 62, seção 1, página 3, 2017.

BRASIL. MINISTÉRIO DA AGRICULTURA, PECUÁRIA E ABASTECIMENTO. Instrução Normativa no 31, de 29 de junho de 2018. Diário Oficial da União, publicado em 02/07/2018, edição 125, seção 1, p. 2, 2018 .

BRASIL. MINISTÉRIO DA AGRICULTURA, PECUÁRIA E ABASTECIMENTO. Instrução Normativa no 76, de 26 de novembro de 2018. Diário Oficial da União, publicado em 30/11/2018, edição 230, seção 1, p. 9, 2018b.

BRASIL. MINISTÉRIO DA AGRICULTURA, PECUÁRIA E ABASTECIMENTO. Instrução Normativa no 77, de 26 de novembro de 2018. Diário Oficial da União, publicado em 30/11/2018, edição 230 , seção 1, p. 10, 2018 c.

BRASIL. MINISTÉRIO DA AGRICULTURA, PECUÁRIA E ABASTECIMENTO. Relação dos planos anuais de amostragem e relatórios dos resultados do PNCRC/ANIMAL, 2019a. Disponível em: <https://www.gov.br/agricultura/pt-br/assuntos/inspecao/produtos-animal/plano-denacional-de-controle-de-residuos-e-contaminantes $>$.

BRASIL. MINISTÉRIO DA AGRICULTURA, PECUÁRIA E ABASTECIMENTO. Plano Nacional de Controle de Resíduos e Contaminantes PNCRC/Animal, 2019b. Disponível em: <https://www.gov.br/agricultura/pt-br/assuntos/inspecao/produtos-animal/plano-denacional-de-controle-de-residuos-econtaminantes/InstruoNormativaN05.2019PNCRC2019.pdf> .

BRITO, J. R. F.; BRITO, M. A. V. P. Qualidade higiênica do leite. EMBRAPA-CNPGL-ADT, Documentos no 62, 1998. 17p. Disponível em: $<$ http://ainfo.cnptia.embrapa.br/digital/bitstream/item/81911/1/Qualidade-higienica-doleite.pdf> .

BRITO, M. A. V. P. Resíduos de antimicrobianos no leite. Embrapa Gado de Leite - Circular Técnica 60. 2000. 28p. Disponível em:

$<$ http://www.infoteca.cnptia.embrapa.br/bitstream/doc/594287/1/Residuodeantimicrobian os.pdf>. 
BRITO, M. A. V. P.; LANGE, C. C. Resíduos de antibióticos no leite. Embrapa Gado de Leite Comunicado Técnico 44. 2005. 4p. Disponível em:

<https://ainfo.cnptia.embrapa.br/digital/bitstream/item/65413/1/COT-44-Residuos-deantibioticos.pdf>.

CASSOLI, L. D.; MACHADO, P. F.; FREITAS, F. A. Diagnóstico de resíduos de antibióticos em amostras de leite provenientes de empresas com sistema de pagamento por qualidade na região sudeste. Veterinária e Zootecnia, v. 20, n. 1, p. 88-89, 2013.

COSTA, E. O. Resíduos de antibióticos no leite: um risco à saúde do consumidor. Revista Higiene Alimentar, v. 10, n. 44, p. 15-17, 1996.

COSTA, E. O.; RAIA, R.; WATANABE, E. T.; et al. Influência do tratamento intramamário de casos de mastite de bovinos em lactação em relação à presença de resíduos de antibióticos no leite dos quartos sadios não tratados. Revista Napgama, v. 3, n. 4, p. 14-17, 2000.

COSTA, E. O. Uso de Antimicrobianos na Mastite. In: SPINOSA, H. L.; GÓRNIAK, S. L.; BERNARDI, M. M. Farmacologia Aplicada à Medicina Veterinária. Rio de Janeiro: Guanabara Koogan, 2015. P. 487-500.

COSTA, R. G.; QUEIROGA, R. C. R. E.; PEREIRA, R. A. G.Influência do alimento na produção e qualidade do leite de cabra. Revista Brasileira de Zootecnia, v. 38, supl. especial, p. 307-321, 2009. Disponível em: <http://www.scielo.br/pdf/rbz/v38nspe/v38nspea31.pdf> .

DAYAN, A. D. Allergy to antimicrobial residues in food: assessment of the risk to man. Veterinary Microbiology, v. 35, n. 3-4, p. 213-226, 1993.

EMBRAPA - EMPRESA BRASILEIRA DE PESQUISA AGROPECUÁRIA. Indicadores, tendências e oportunidades para quem vive no setor leiteiro. Anuário Leite 2018, 116 p. Disponível em: <https://www.embrapa.br/busca-de-noticias/-/noticia/36560390/anuario-do-leite-2018-elancado-na-agroleite> .

ESTEVÃO NETO, A.; GARINO JÚNIOR, F.; SANTOS, J. C. A.; et al. Avaliação de resíduo de antibiótico em amostras de leite de vacas após a terapia de vacas secas. Arquivos do Instituto Biológico, v. 82, p. 1-4, 2015. doi: 10.1590/1808-1657000322013

FERNANDES, V. G.; MARICATO, E. Análises físico-químicas de amostras de leite cru de um laticínios em Bicas/MG. Revista do Instituto de Laticínios Cândido Tostes, v. 65, n. 375, p. 310, 2010. Disponível em: <https://www.revistadoilct.com.br/rilct/article/view/129/134> .

FERREIRA, A. R. P.; MACEDO, L. S. O.; ROCHA, T. S.; et al. Resíduos de antibióticos em leite in natura utilizado para processamento em laticínio localizado no município de Teresina Piauí. Acta Tecnológica, v. 9, n. 1, 2014. 
FULLER, R. Probiotics in man and animals. Journal of Applied Bacteriology, v. 66, n. 5, p. 365-378, 1989.

FUSCO, M. A.; OLIVEIRA, V. V. S.; PEPE, V. L. E. Farmacovigilância veterinária e a saúde humana: uma revisão dos programas selecionados de notificação de eventos adversos a medicamentos veterinários. Archives of Veterinary Science, v. 15, n. 1, p. 49-61, 2010.

IBGE - INSTITUTO BRASILEIRO DE GEOGRAFIA E ESTATÍSTICA. Indicadores IBGE - Estatística da produção pecuária, 2019. 83p. Disponível em:

<https://biblioteca.ibge.gov.br/visualizacao/periodicos/2380/epp_2018_4tri.pdf> .

IZZO, L.; RODRÍGUEZ-CARRASCO, Y.; TOLOSA, J.; et al. Target analysis and retrospective screening of mycotoxins and pharmacologically active substances in milk using an ultra-highperformance liquid chromatography/high-resolution mass spectrometry approach. Journal of Dairy Science, v. 103, n. 2, p. 1250-1260, 2020.

JONES, G. M.; SEYMOUR, E. H. Cowside Antibiotic Residue Testing. Journal of Dairy Science, v. 71, n. 6, p. 1691-1699, 1988.

JONES, G. M. On-farm Tests for Drug Residues in Milk. Virginia Cooperative Extension, p. 15, 2009. Disponível em: <http://pubs.ext.vt.edu/content/dam/pubs_ext_vt_edu/404/404401/404-401_pdf.pdf>.

KISSELL, L. W.; BAYNES, R. E.; RIVIERE, J. E.; et al. Occurrence of flunixin residues in bovine milk samples from the USA. Food Additives \& Contaminants: Part A, v. 30, n. 9, p. 15131516, 2013.

KHANAL, B. K. S.; SADIQ, M. B.; SINGH, M.; et al. Screening of antibiotic residues in fresh milk of Kathmandu Valley, Nepal. Journal of Environmental Science and Health: Part B, v. 53, n. 1, p. 57-86, 2018.

KORB, A.; BRAMBILLA, D. K.; TEIXEIRA, D. C.; et al. Riscos para a saúde humana do uso de antibióticos na Cadeia Produtiva Leiteira. Revista de Saúde Pública de Santa Catarina, v. 4, n. 1, p. 21-36, 2011.

KOSGEY, A.; SHITANDI, A.; MARION, J. W. Antibiotic Residues in Milk from Three Popular Kenyan Milk Vending Machines. The American Journal of Tropical Medicine and Hygiene, $v$. 98, n. 5, p. 1520-1522, 2018.

LOPES, M. O. Levantamento do uso e detecção da presença de antimicrobianos no leite produzido na região metropolitana de Curitiba - PR. Curitiba: UFP, 2002. 119p. Dissertação (Mestrado em Ciências Veterinárias), Setor de Ciências Agrárias, Universidade Federal do Paraná, 2002. Disponível em:

$<$ https://acervodigital.ufpr.br/bitstream/handle/1884/42033/D\%20-

\%20MARCIA\%20OLIVEIRA\%20LOPES.pdf?sequence=3> . 
MACHADO, T. R. O.; CORREA, M. G.; MARIN, J. M. Antimicrobial susceptibility of coagulasenegative staphylococci isolated from mastitic cattle in Brazil. Arquivo Brasileiro de Medicina Veterinária e Zootecnia, v. 60, n. 1, p. 278-282, 2008.

MARTIN, J. G. P. Resíduos de antimicrobianos em leite - uma revisão. Segurança Alimentar e Nutricional, v. 18, n. 2 p. 80-87, 2011.

MATTOS, M. R.; BELOTI, V.; TAMANINI, R.; et al. Qualidade do leite cru produzido na região do agreste de Pernambuco, Brasil. Semina: Ciências Agrárias, v. 31, n. 1, p. 173-182, 2010.

MERCOSUL - MERCADO COMUM DO SUL. Resolução GMC no 54/2000, dispõe sobre metodologias analíticas, ingesta diária admissível e limites máximos de resíduos para medicamentos veterinários em alimentos de origem animal, 2000. Disponível em: <http://www.inmetro.gov.br/barreirastecnicas/PDF/GMC_RES_2000-054.pdf> .

MITCHELL, J. M.; GRIFFITHS, M. W.; MCEWEN, A.; et al. Antimicrobial drug residues in milk and meat: causes, concerns, prevalence, regulations, tests, and tests performance. Journal of Food Protection, v. 61, n. 6, p. 742-756, 1998.

MOGHADAM, M. M.; AMIRI, M.; RIABI, H. R.; et al. Evaluation of Antibiotic Residues in Pasteurized and Raw Milk Distributed in the South of Khorasan-e Razavi Province, Iran. Journal of Clinical \& Diagnostic Research, v. 10, n. 12, p. FC31-FC35, 2016.

MONTEIRO, A. A.; TAMANINI, R.; SILVA, L. C. C.; et al. Características da produção leiteira da região do agreste do estado de Pernambuco, Brasil. Semina: Ciências Agrárias, v. 28, n. 4, p. 665-674, 2007.

NERO, L. A.; MATTOS, M. R.; BELOTI, V.; et al.Resíduos de antibióticos em leite cru de quatro regiões leiteiras no Brasil. Ciência e Tecnologia de Alimentos, v. 27, n. 2, p. 391-393, 2007.

NIJSTEN, R.; LONDON, N.; VAN DEN BOGAARD, A.; et al. Antibiotic resistance of enterobacteriaceae isolated from the faecal flora of fattening pigs. Veterinary Quarterly, $v$. 15, n. 4, p. 152-157, 1993.

NOVAES, S. F.; SCHREINER, L. L.; SILVA, I. P.; et al. Residues of veterinary drugs in milk in Brazil. Ciência Rural, v. 47, n. 8, 2017.

NUNES, E. R. C.; PINHEIRO JÚNIOR, J. W.; MEDEIROS, E. V.; et al. Resíduos de antimicrobianos em leite in natura na microrregião de Garanhuns, Pernambuco. Revista Brasileira de Medicina Veterinária, v. 38, n. 2, p. 157-162, 2016. 
OMS - ORGANIZACIÓN MUNDIAL DE LA SALUD. Producción de alimentos de origen animal. 2. ed. Roma: FAO/OMS, 2009. Disponível em:

<http://www.fao.org/docrep/012/i1111s/i1111s.pdf> .

PACHECO-SILVA, É.; SOUZA, J. R.; CALDAS, E. D. Resíduos de medicamentos veterinários em leite e ovos. Química Nova, v. 37, n. 1, p. 111-122, 2014.

PRADO, C. K.; FERREIRA, F. D.; BANDO, E.; et al. Oxytetracycline, tetracycline, chlortetracycline and doxycycline in pasteurised cow's milk commercialised in Brazil. Food Additives \& Contaminants: Part B, v. 8, n. 2, p. 81-84, 2015.

QU, Y.; ZHAO, H.; NOBREGA, D. B.; et al. Molecular epidemiology and distribution of antimicrobial resistance genes of Staphylococcus species isolated from Chinese dairy cows with clinical mastitis. Journal of Dairy Science, v. 102, n. 2, p. 1571-1583, 2019.

RAMA, A.; LUCATELLO, L.; BENETTI, C.; et al. Assessment of antibacterial drug residues in milk for consumption in Kosovo. Journal of Food and Drug Analysis, v. 25, n. 3, p. 525-532, 2017.

ROCA, M.; VILLEGAS, L.; KORTABITARTE, M. L.; et al. Effect of heat treatments on stability of $\beta$-lactams in milk. Journal of Dairy Science, v. 94, n. 3, p. 1155-1164, 2011.

SANTOS, M. V.; FONSECA, L. F. L. Estratégias para controle de mastite e melhoria da qualidade do leite. Barueri: MANOLE, 2007. 314p.

SANTOS, A. F. S.; MARTINS, T.; MIRANDA, M. S.; et al. Antimicrobial residues in milk and occurrence of clinical and subclinical mastitis in herds in the region of Campinas, São Paulo. Acta Veterinaria Brasilica, v. 8, n. 1, p. 60-67, 2014.

SCHENCK, F. J.; FRIEDMAN, S. L. The effect of storage at 4 degrees $C$ on the stability of ampicilin residues in raw milk. Journal of the American Veterinary Association, v. 217, n. 4, p. 541-545, 2000.

SCHLEMPER, V.; SACHET, A. P. Antibiotic residues in pasteurized and unpasteurized milk marketed in southwest of Paraná, Brazil. Ciência Rural, v. 47, n. 12, 2017.

SILVA, D. P.; SILVA, A. D. P.; MELO, J. D. G.; et al. Ocorrência de resíduos de antibióticos em leite de células de refrigeração da região sul do Estado do Pará. Revista Brasileira de Produtos Agroindustriais, v. 16, n. 4, p 359-368, 2014.

SOUSA, F. C.; SILVA, L. M. M.; SILVA, J. N.; et al. Resíduos de antibiótico em amostras de leite pasteurizado tipo $\mathrm{C}$ comercializado na região caririense. Revista Verde de Agroecologia e Desenvolvimento Sustentável, v. 7, n. 2, p 289-295, 2012. 
SOUZA, L. B.; PINHEIRO, C. G. M. E.; GERALDO NETO, S. A.; et al. Resíduos de antimicrobianos em leite bovino cru no estado do Rio Grande do Norte. Ciência Animal Brasileira, v. 18, p. 16, 2017.

SPISSO, B. F.; NOBREGA, A. W.; MARQUES, M. A. S. Resíduos e contaminantes químicos em alimentos de origem animal no Brasil: histórico, legislação e atuação da vigilância sanitária e demais sistemas regulatórios. Ciência \& Saúde Coletiva, v. 14, n. 6, p. 2091-2106, 2009.

TEMPINI, P. N.; ALY, S. S.; KARLE, B. M.; et al. Multidrug residues and antimicrobial resistance patterns in waste milk from dairy farms in Central California. Journal of Dairy Science, $v$. 101, n. 9, p. 8110-8122, 2018.

TETENS, J. L.; BILLERBECK, S.; SCHWENKER, J. A.; et al. Selection of extended-spectrum $\beta$ lactamase-producing Escherichia coli in dairy calves associated with antibiotic dry cow therapy-A cohort study. Journal of Dairy Science, v. 102, n. 12, p. 11449-11452, 2019.

VIEIRA, T. S.; RIBEIRO, M. R.; NUNES, M. P.; et al. Detecção de resíduos de antibióticos em amostras de leite pasteurizado do Estado do Paraná, Brasil. Semina: Ciências Agrárias, v. 33, n. 2, p. 791-795, 2012.

Autor para correspondência: João Rodrigo Gil de los Santos Departamento de Veterinária Preventiva, Faculdade de Veterinária, Universidade Federal de Pelotas, Campus Universitário, prédio 1, 2o andar, Capão do Leão (RS), CEP 96160-000. joao.gil@ufpel.edu.br 